\title{
Radio-detoxified LPS alters bone marrow- derived extracellular vesicles and endothelial progenitor cells
}

Hargita Hegyesi ${ }^{1,2 *}$ (D) Nikolett Sándor², Géza Sáfrány², Virág Lovas ${ }^{1}$, Árpád Kovács ${ }^{1}$, Angéla Takács ${ }^{1}$, László Kőhidai ${ }^{1}$, Lilla Turiák ${ }^{3}$, Ágnes Kittel ${ }^{4}$, Krisztina Pálóczi ${ }^{1}$, Lóránd Bertók ${ }^{2}$ and Edit Irén Buzás ${ }^{1,5}$

\begin{abstract}
Stem cell-based therapies raise hope for cell replacement and provide opportunity for cardiac regenerative medicine and tumor therapy. Extracellular vesicles are a membrane-enclosed intercellular delivery system with the potential to improve the therapeutic efficacy of the treatment of a variety of disorders. As the incidence of breast cancer continues to rise, radiotherapy has emerged as a leading treatment modality. Radiotherapy also increases the risk of coronary heart disease and cardiac mortality. In a chest-irradiated mouse model of cardiac injury, we investigated the effects of local irradiation. We found an increased lethality after 16 Gy irradiation. Importantly, radio-detoxified LPS (RD-LPS) treatment prolonged the survival significantly. By flow cytometry, we demonstrated that upon administration of RD-LPS, the number of bone marrow-derived endothelial progenitor cells increased in the bone marrow and, in particular, in the circulation. Furthermore, mass spectrometry analysis showed that RD-LPS altered the proteomic composition of bone marrow cell-derived small extracellular vesicles (sEVs). RD-LPS treatment increased interferon-induced transmembrane protein-3 (IFITM3) expression markedly both in bone marrow cells and in bone marrow cell-derived small extracellular vesicles. This is the first study to demonstrate that radio-detoxified LPS treatment induces an increase of circulating endothelial progenitor cells (EPCs) in parallel with a reduced radiotherapy-related mortality. While the total number of bone marrow-derived extracellular vesicles was significantly increased $24 \mathrm{~h}$ after treatment in the RD-LPS groups, the number of endothelial progenitor cells was reduced in animals injected with GW4896 (a chemical inhibitor of exosome biogenesis) as compared with controls. In contrast to these in vivo results, in vitro experiments did not support the effect of sEVs on EPCs. Our data raise the intriguing possibility that IFITM3 may serve as a marker of the radio-detoxified LPS treatment.
\end{abstract}

Keywords: Endothelial progenitor cell, Radio-detoxified endotoxin, Extracellular vesicles, Exosomes, Bone marrow, IFITM3

\section{Introduction}

Stem cell therapy holds promise for tissue regeneration, but the direct replacement of cells in the damaged part of the tissue is limited and the survival of cells still remain questionable [1]. Tissue injury in the heart, lung, and bone marrow (BM) are among the most important side effects of breast cancer radiotherapy, which limits

\footnotetext{
* Correspondence: hegyesi.hargita@med.semmelweis-univ.hu

'Department of Genetics, Cell- and Immunobiology, Semmelweis University, Budapest, Hungary

${ }^{2}$ National Research Directorate for Radiobiology and Radiohygiene, National Public Health Center, Budapest, Hungary

Full list of author information is available at the end of the article
}

the success of tumor treatment [2-4]. However, the mechanisms through which ionizing radiation induces BM injury remains poorly understood [5]. Experimental models such as the murine radiation-induced cardiomyopathy model have proven useful to study the therapeutic approaches that mitigate radiation injury [6-8].

Several studies have demonstrated the protective effects of radio-detoxified (gamma irradiation-fragmented) lipopolysaccharide (RD-LPS), also referred to as Tolerin [9], in reducing radiation-induced tissue damage [10]. In the present study, we investigated for the first time the effects of RD-LPS in a cardiotoxicity model. We focused on endothelial progenitor cells (EPCs) and BM cell-derived

(c) The Author(s). 2019 Open Access This article is distributed under the terms of the Creative Commons Attribution 4.0 International License (http://creativecommons.org/licenses/by/4.0/), which permits unrestricted use, distribution, and 
small extracellular vesicles (sEVs) as potential biomarkers of the RD-LPS effect. BM-derived EPCs have been shown to have regenerative potential in cardiac diseases both in preclinical and clinical settings [11]. Recently, circulating EPCs have been suggested as sensitive and reproducible markers of endothelial dysfunction caused by ionizing radiation [12]. In addition, EPCs carry both endothelial cell markers (such as VEGFR-2 and CD31) $[13,14]$ and one or more stem cell antigens such as CD34 [15].

Rapidly accumulating data indicate that cells release extracellular vesicles (EVs) that mediate cell-cell communication by shuttling lipids, nucleic acids, metabolites, and proteins to recipient cells [16]. The cargo of EVs is cell- and disease-type related and confers specific features to EVs, mediating their biological functions [1719]. In our chest-irradiated mouse model, here we investigated not only EPCs but also EVs as potential novel mediators of the effect induced by RD-LPS. In this study, the biogenesis of EVs was not addressed, and therefore, we referred to EVs based on their size only [18].

Interferon-induced transmembrane protein 3 (IFITM3) was initially described in development, apoptosis, cell proliferation, and cell signaling [20,21]. Also, recently, it was suggested that ectopic expression of IFITM3 could restrict infection by viruses [22], by potently inhibiting EV-cell fusions. Here we addressed the question concerning the role of IFITM3 in the RD-LPS-induced EPC activation.

\section{Materials and methods}

\section{Animals and irradiation}

C57BL/6 mice (Charles River Laboratories) were exposed to local 16 Gy chest irradiation as described previously [23]. Mice were irradiated by a $250-\mathrm{kV}$ X-ray irradiator (THX-250) using a dose rate of $1.23 \mathrm{~Gy} / \mathrm{min}$. A special lead shield was used to deliver a localized dose of radiation to the heart region only. Survival was monitored daily, and the experiment was terminated 250 days post-irradiation.

\section{Histology and morphometric analysis}

After 250 days following irradiation, the animals were sacrificed by cervical dislocation, and the total body weight and the heart weight were measured. The hearts were excised and divided into two pieces on the vertical axis (for DNA isolation and for morphometric analysis). The tissues were fixed in formalin overnight and embedded in paraffin. Blocks were sectioned in 4- $\mu \mathrm{m}$ cross-sectioned slices and stained with Van Gieson staining to determine the extent of collagen, indicative for fibrosis [24]. The slides were photographed with Nikon Eclipse $80 \mathrm{i}, \times 20$ objective, 10 random fields per slide were taken into consideration. Of these sections, 4 were analyzed per heart. In total, we analyzed 160 images to evaluate a cross-sectional area of myocytes by ImageJ program $[25,26]$.

\section{Detection of the common deletion (3867 bp) in the mitochondrial genome by $\mathrm{qPCR}$}

Total DNA (genomic and mitochondrial together) was isolated from the heart tissues with the MasterPure DNA Purification kit (Epicenter) following the manufacturer's instructions. DNA concentration was measured by spectrophotometry. The amount of deleted mtDNA copies was estimated by real-time PCR, relative to the nuclear GAPDH gene. The primers were the GAPDH-F: TCACCACCATGGAGAAGGC, R: GCTA AGCAGTTGGTGGTGCA and the delMT-F: TCATTC TAGCCTCGTACC AACA, R: GAGGTCTGGGTCAT TTTCGTTA, respectively. QPCR reactions are carried out using the SYBR Green PCR kit (Bioline), in a Corbett RG 6000 instrument.

\section{Bone marrow cell apoptosis measurement}

$\mathrm{BM}$ was isolated from the femora of mice by flushing the shaft with PBS. For apoptosis measurements, $1 \times 10^{6}$ BMCs per animal were incubated with 3\% BSA for $20 \mathrm{~min}$. After washing cells once with cell culture media (RPMI1640; Gibco), samples were resuspended in $100 \mu \mathrm{l}$ of annexin $\mathrm{V}$ binding buffer (BD Pharmingen) containing Lin cocktail-APC (Miltenyi), and annexin V-FITC (Themo Fisher Scientific). Before analysis, $1 \mu \mathrm{l}$ of Topro-3 $(1 \mu \mathrm{g} / \mathrm{ml}$; Invitrogen) was added to the samples. After washing them once with PBS, we measured samples by using a FACSCalibur (BD Bioscience).

Measurement of EPC differentiation, and Dil-ac-LDL uptake $\mathrm{BM}$ isolated from femurs were collected in endothelial growing media (EGM)-2 complete medium (Lonza). BMCs were seeded onto six-well plates at a final density of $1.5 \times 106$ cells. Twenty-four hours after seeding, nonadherent cells were removed and attached cells were further cultured at $37^{\circ} \mathrm{C}$ and $5 \%$ of $\mathrm{CO}_{2}$. Culture media was changed every 2 days until the first EPC colonies appeared or up to 10 days. EPCs were incubated with 1 , $1^{\prime}$-dioctadecyl-3,3,3',3' - tetramethylindo-carbocyaninelabeled Ac-LDL (Dil-ac-LDL, Life Technologies), fixed with $4 \%$ paraformaldehyde, and measured by flow cytometry (FACSCalibur, BD Bioscience), and for morphological studies, the stained samples were observed on a fluorescent microscope (Zeiss Celldiscoverer). Pictures were taken with a $\times 20$ objective magnification.

\section{Isolation of small extracellular vesicles}

BM cells (BMCs) were cultured in RPMI-1640 (Thermo Fisher Scientific) supplemented with penicillin $(100 \mathrm{U} / \mathrm{ml})$, streptomycin $(100 \mu \mathrm{g} / \mathrm{ml})$, and L-glutamine $(2 \mathrm{mM})$ (all from Sigma) and 2.5\% EV-free fetal calf serum (Gibco). After $24 \mathrm{~h}$, the conditioned medium was centrifuged at $600 \mathrm{~g}$ for $10 \mathrm{~min}$ to remove cells. The supernatant was filtered through a $5-\mu \mathrm{m}$ filter then centrifuged at $2000 \mathrm{~g}$ for 
$30 \mathrm{~min}$ at $4{ }^{\circ} \mathrm{C}$. Subsequently, supernatants were filtered again through a $0.8-\mu \mathrm{m}$ membrane and centrifuged at 12 , $500 \mathrm{~g}$ for $30 \mathrm{~min}$ at $4{ }^{\circ} \mathrm{C}$. The supernatant was next filtered through a $0.2-\mu \mathrm{m}$ filter and pelleted at $100,000 \mathrm{~g}$ for 70 min at $4{ }^{\circ} \mathrm{C}$ using an MLA-55 rotor in an Optima Max XP ultracentrifuge (Beckman-Coulter). The small EV (sEV)enriched pellet was washed once with PBS and resuspended in $50 \mu \mathrm{l}$ PBS. The particles in the resuspended pellet were analyzed by tunable resistive pulse sensing (TRPS, qNano, Izon Sciences) [27]. The protein content of the $\mathrm{sEV}$-enriched preparations was determined by the MicroBCA assay (Pierce). The IFITM3 content was determined by a commercial ELISA kit (MyBiosource).

\section{Flow cytometry analysis of EPCs and sEVs}

$\mathrm{BM}$ cells were stained with PE-conjugated anti-CD34-PE and anti-VEGFR2-PerCP/Cy5.5 antibodies (Sony). Blood samples were collected into EDTA tubes, red blood cells were lysed, and anti-CD34-PE and CD31-FITC (Sony) as well as an isotype control (rat IgG2a, Sony) were used to detect EPCs. Labeled cells were detected with a flow cytometer (FACSCalibur, BD Bioscience), and analysis was performed using the CellQuest and FlowJo softwares.

For sEV analysis, EV-enriched pellet was incubated with $1 \mu \mathrm{g}$ of $4 \mu \mathrm{m}$ aldehyde/sulfate latex beads (Invitrogen) for $15 \mathrm{~min}$ in $50 \mu \mathrm{l}$ of $0.9 \% \mathrm{NaCl}$-HEPES puffer followed by an overnight incubation at $4{ }^{\circ} \mathrm{C}$ with agitation. The reaction was stopped by incubation with $100 \mathrm{mM}$ glycine for $30 \mathrm{~min}$ at room temperature. sEV- or BSA-coated beads were washed with $1 \%$ PBS-BSA, blocked with $0.2 \%$ Tropix I-Block (Thermo) and incubated with either anti-CD81$\mathrm{PE}$ (BD Bioscience) or isotype control (Armenian hamster IgG2), anti-CD63-PE (BioLegend), anti-CD107a PerCP/ Cy5.5 (LAMP2, Sony), anti-CD9-PE (Abcam), isotype control (rat IgG2a) or anti-IFITM3 (ProteinTech), and a goat anti-rabbit IgG-Cy2 (Abcam) in PBS-BSA $1 \%$ for $30 \mathrm{~min}$ at $4{ }^{\circ} \mathrm{C}$. Next, the samples were washed and analyzed on a FACSCalibur flow cytometer (BD Bioscience).

\section{In vivo treatment of mice with GW4869}

C57BL/6 mice (10 to 12 weeks of age) were randomly assigned to be injected with PBS, RD-LPS, or GW4869+RDLPS ( $n=5$ per group). GW4869 (Sigma) was dissolved in DMSO $(0.005 \%)$ and injected i.p. at a single dose of $25 \mu \mathrm{g} /$ mouse. Mice in the GW4869+RD-LPS group were pre-injected i.p. with $20 \mu \mathrm{g}$ RD-LPS $1 \mathrm{~h}$ prior to the i.p. injection of GW4869. Twenty-four hours later, the femurs were removed and BMCs were isolated.

\section{Transmission electron microscopy}

The sEV pellets were fixed with $4 \%$ paraformaldehyde, washed with PBS, and post-fixed in $1 \% \mathrm{OsO}_{4}$ for $30 \mathrm{~min}$ as previously published [28]. After rinsing with distilled water, pellets were dehydrated in graded ethanol, including block staining with $1 \%$ uranyl-acetate in 50\% ethanol for $30 \mathrm{~min}$, and were embedded in Taab 812 . Overnight polymerization of samples at $60^{\circ} \mathrm{C}$ was followed by sectioning and analysis using a Hitachi 7100 electron microscope (Hitachi Ltd).

\section{Protein identification using LC-MS (MS)}

EV pellets were resuspended in $25 \mu \mathrm{L}$ HPLC water and proteins were extracted as described previously [29]. The resulting peptides were desalted using Pierce ${ }^{\text {mit }} \mathrm{C} 18$ spin columns (Thermo). Peptides were analyzed using a Waters nanoACQUITY UPLC (Waters) coupled to a high-resolution maXis II QTOF mass spectrometer equipped with CaptiveSpray nanoBooster ionization source (Bruker). Peptides were separated using gradient elution on a $25-\mathrm{cm}$ Waters Peptide BEH C18 nanoACQUITY $1.7 \mu \mathrm{m}$ particle size UPLC column. Data were processed using proteinScape 3.0 software (Bruker). Proteins were identified using Mascot (version 2.5, Matrix Science) search engine against the Swissprot Mus musculus database (accessed on 09/2017). The following parameters were used: trypsin enzyme, $7 \mathrm{ppm}$ peptide mass tolerance, $0.05 \mathrm{Da}$ fragment mass tolerance, two missed cleavages. Carbamidomethylation was set as fixed modification, while deamidation $(\mathrm{NQ})$ and oxidation $(\mathrm{M})$ as variable modifications. Proteins with a minimum of two identified, unique peptides were accepted. Gene ontology enrichment was performed using g:Profiler [30]. Label-free quantification was performed using MaxQuant [31] software version 1.5.3.30. Each LC-MS/MS run was aligned using the "match between runs" feature (match time window $0.8 \mathrm{~min}$, alignment time window $15 \mathrm{~min}$ ).

\section{Silencing IFITM3 by lentiviral particle containing shRNA}

The commercially available lentiviral particles (Santa-Cruz) were named as sh-IFITM3 or sh-control (scrambled). Recombinant lentiviral vectors expressing IFITM3 shRNA or control shRNA constructs at multiplicity of infection $(\mathrm{MOI})=50$ were transduced in the presence of $8 \mu \mathrm{g} / \mathrm{ml}$ polybrene into freshly isolated BM cells. Knockdown of IFITM3 RNA was confirmed by qRT-PCR and on protein level with flow cytometry. Total RNA was extracted from BM cells 2 days after infection using the RNeasy Mini Kit (Qiagen). cDNA was synthesized using the SensiFAST cDNA Synthesis Kit (Bioline). Real-time quantitative PCR analysis was performed using the SYBR Green Master Mix Kit (Bioline) on a 7900HT real-time PCR platform (Thermo Fisher Scientific). For relative quantification, $2-{ }^{\Delta \Delta C T}$ was calculated. The primer sequences for PCR amplification of the IFITM3 gene were $5^{\prime}$-TGTCCAAACCTTCTTCTCTCC-3' and 5'CGTCGCCAACCATCTTCC-3'. GAPDH was applied as an internal control. 


\section{Statistics}

Survival rates were analyzed by the Kaplan-Meyer test. Data from $>3$ groups were analyzed by non-repeated measures ANOVA with Dunnett's test for comparison with the control. Unpaired two-tailed Student's $t$ test was used to analyze data between two groups. For all data analysis, we used GraphPad Prism 8.0.2.

\section{Results}

\section{Radioprotective effect of RD-LPS}

In the present study, we addressed the question whether radio-detoxified LPS (RD-LPS) has a protective role if administered i.p. $1 \mathrm{~h}$ after local thorax irradiation (IR) of mice (Fig. 1a). As shown in Fig. 1b, most mice died between days 133-169 post-irradiation. The median survival was 141 days in the 16-Gy-irradiated group and 180 days in the irradiated and RD-LPS-treated mice (logrank Mantel-Cox test, $p<0.001)$. In $\mathrm{C} 57 \mathrm{Bl} / 6$ mice, the number of PBMCs decreased in the heart-irradiated groups $24 \mathrm{~h}$, and 1 week post-irradiation, the number of BMCs decreased at $24 \mathrm{~h}$ in the RD-LPS+16 Gy groups and 1 week post-irradiation in the RD-LPS group (Additional file 1). The 16-Gy-treated animals developed bilateral ventricular hypertrophy as evidenced by gravimetry after 250 days, but RD-LPS protected against radiationinduced myocyte hypertrophy (Additional file 2). Hearts of irradiated and RD-LPS-treated mice were further examined for evidence of pathologic alterations [32]. Van Gieson staining showed slight interstitial fibrosis in the irradiated heart 250 days after 16 Gy and RD-LPS+16 Gy (Fig. 1c). Quantitative analysis of the images indicated a significant increase of myocyte size 250 days after $16 \mathrm{~Gy}$ $(p<0.001)$ and RD-LPS+16 Gy $(p<0.05)$ compared with control mice (Fig. 1d). Mitochondrial DNA deletion, as a molecular marker of cardiomyocyte damage was assessed [33]. The results showed that the formation of mtDNA deletion in early and late time points in the irradiated groups was higher than in the controls, but this difference was significant only at 250 days post-irradiation $(p<0.05)$. Preventive effect of RD-LPS was also detected (Fig. 1e).

\section{RD-LPS enhances the mobility and migration of EPCs}

Next, we set to examine the number of EPCs in the BM of experimental groups of mice. As shown in Fig. 1f, the number of EPCs was higher in the groups of mice injected with RD-LPS with or without irradiation as compared to the PBS-injected controls $(p<0.001$ for both groups). We also analyzed EPCs in blood samples of mice and also found a significant difference between the above groups $(p<0.001$ and $p<0.005$, respectively, see Fig. 1g). Since RD-LPS stimulated the differentiation and also the release of EPCs into the circulation, we speculated that RD-LPS may promote the survival of BM stem cells and the uptake of ac-LDL by EPCs. To test this, isolated BMCs were treated with RD-LPS for $24 \mathrm{~h}$ and the apoptosis of lineage-negative stem cells were measured by flow cytometry. The proportion of early apoptotic cells were $10.39 \pm 1.6 \%$ in the control group and $2.99 \pm 0.7$ in the RD-LPS group $(p=0.0002)$ as shown in Fig. 2a and Additional file 3, while late apoptosis (annexin V and TO-PRO positive cells) did not show significant differences (data not shown).

Next, BM cells were cultured in an endothelial induction medium (EGM2, Lonza) to obtain endothelial progenitor cells. To identify the resulting EPCs, we measured surface markers CD34 and VEGFR2 and the expression of endothelial specific mRNAs CD31 and VE-cadherin and also investigated the physiologic functions of these cells by monitoring DiI-labeled acetylated LDL (DiI-ac-LDL) endocytosis [34]. Following in vitro treatment with RD-LPS, EPCs were incubated for $4 \mathrm{~h}$ with DiI-ac-LDL and cellassociated fluorescence was analyzed by fluorescence microscopy (Zeiss Celldiscoverer, Additional file 4, panels AC) and quantitated by flow cytometry. As shown in Fig. 2b, treatment with RD-LPS led to a significant increase in cell association (a combination of binding and uptake) of DiI-ac-LDL. To investigate the effects of RD-LPS on EPC, the biological factors associated with matured endothelial cells were measured by real-time RT-PCR. The expression of two markers (CD31 and VE-cadherin) were elevated in the RD-LPS-treated group as compared to the PBS group (Additional file 4, panels D-E). CD31 increased by $3.89 \pm 0.5$ fold, whereas VE-cadherin increased by $10.68 \pm 3.8$ fold.

\section{Effect of RD-LPS on BM-derived small extracellular vesicles}

Subsequently, we examined whether blocking the generation of sEVs would modulate the RD-LPS-induced EPC response. To delineate the possible involvement of sEVs in the RD-LPS-induced changes in EPC numbers, we investigated the in vivo effects of GW4869. GW4869 is a neutral sphingomyelinase inhibitor reported to inhibit the ESCRT-independent sEV biogenesis [35]. Indeed, GW4869 attenuated the RD-LPS-induced increase in EPC number in BM (Fig. 2c).

To confirm that BM cells secrete RD-LPS-induced sEVs, we isolated sEVs from primary BMCs. Transmission electron microscopy (TEM) confirmed the presence and morphology of the sEVs (Fig. 2d). Next, we analyzed the particle size distribution and concentration of our sEV-enriched preparations by TRPS. Figure 2e shows representative size distribution of EVs from BMCs isolated from control (upper histogram) and RD-LPSinjected mice (lower histogram) which corresponded to the size range of sEVs and did not differ between the experimental groups. Of note, RD-LPS induced an order of magnitude higher number of EVs as compared to PBS controls (Fig. 2e). Using flow cytometry, we confirmed 


\section{A}

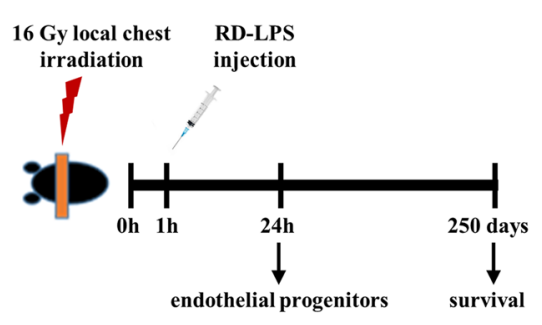

C

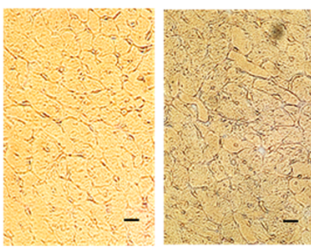

PBS

E

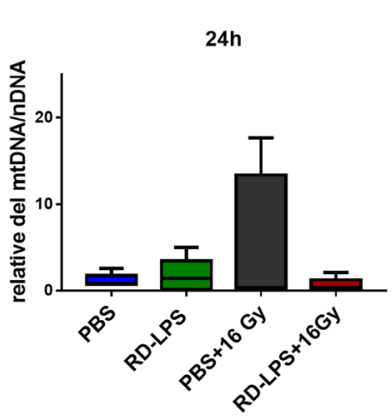

F

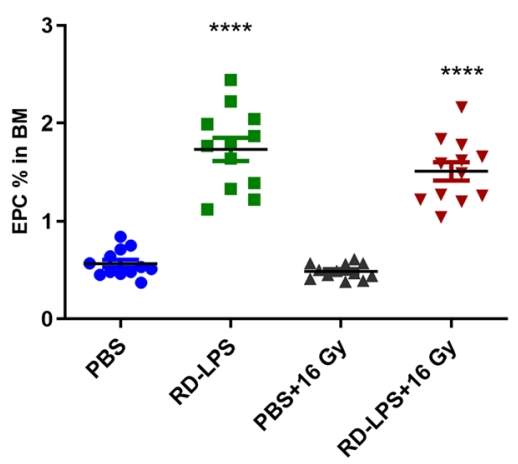

B

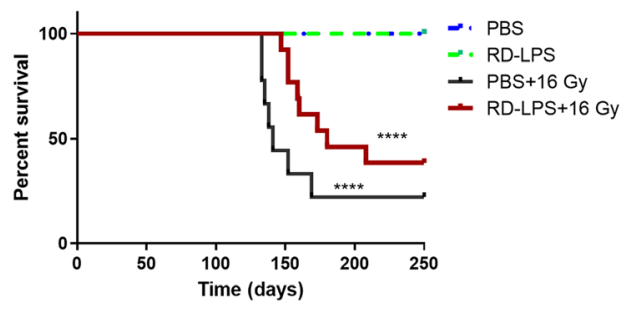

D

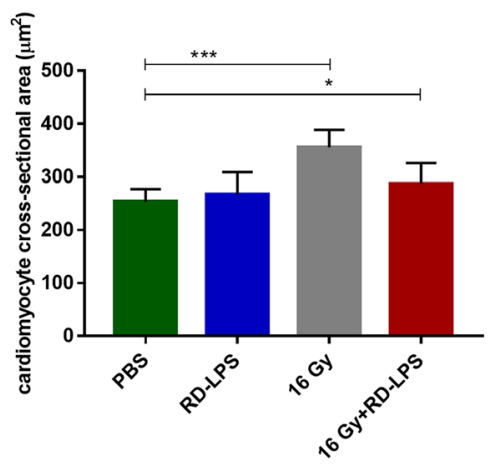

250d

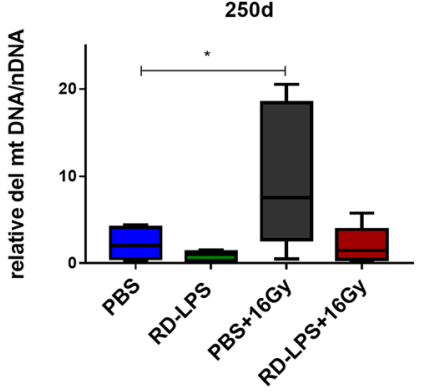

G

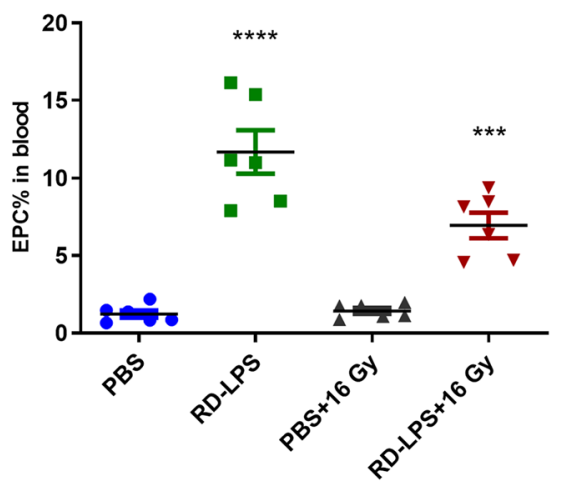

Fig. 1 Effect of local chest irradiation and RD-LPS treatment. a A schematic illustration of the experimental setup. Hearts of C57BL/6 mice received a 16-Gy single dose of X-ray radiation. b Kaplan-Meyer diagram shows the changes of survival in animals treated with PBS, PBS+16 Gy of X-ray, RD-LPS (20 $\mathrm{\mu g} / \mathrm{mouse})$ or 16 Gy combined with RD-LPS ( $n=9-10 /$ group). $p<0.001$, Log-rank Mantel-Cox test. c Representative images of histopathologic changes at 250 days after local heart irradiation. Interstitial fibrosis and degeneration of cardiomyocytes after 16 Gy are indicated (arrows). Van Gieson staining, $\times 20$ objective magnification. Scale bar: $50 \mu \mathrm{m}$. d Morphometric analysis of cardiomyocyte cross-sectional area 250 days post-treatment. Original magnification $\times 20$. Quantitative analysis of myocyte cross-sectional area is shown; ${ }^{*} p<0.05$ and ${ }^{* * *} p<0.005$ vs. PBS-treated animals. e RD-LPS protects against the radiation-induced accumulation of deleted mitochondrial DNA. Copy number was evaluated with $\mathrm{qPCR}$ as detailed in "Materials and methods". $\mathbf{f}$ Flow cytometry analysis of EPCs in the BMCs and $\mathbf{g}$ in the circulation. One-way ANOVA, ${ }^{* *} p<0.01 ;{ }^{* * *} p<0.001, n=6-12$ /group. Mean \pm SD values are shown 
A

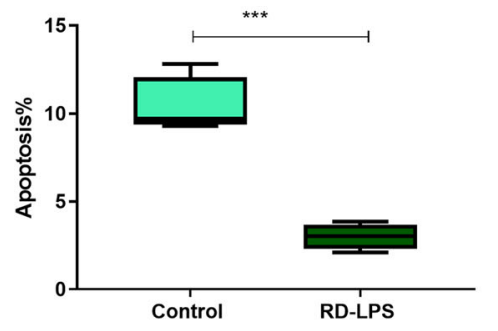

C

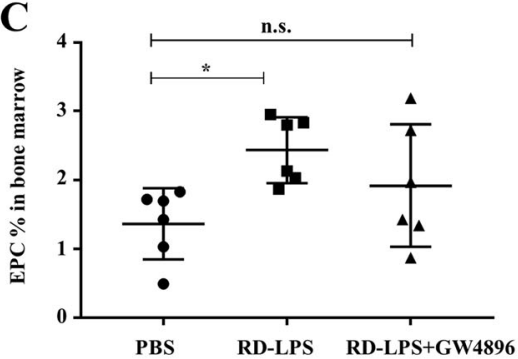

E
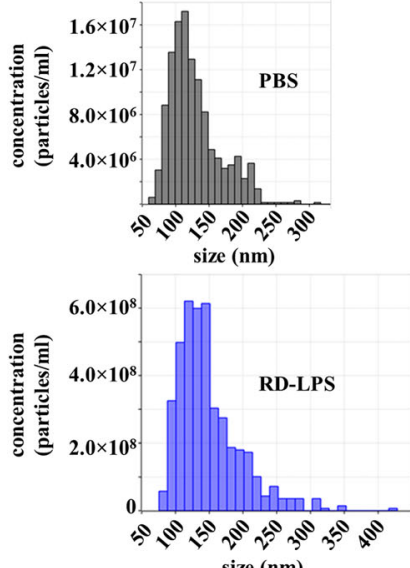

G

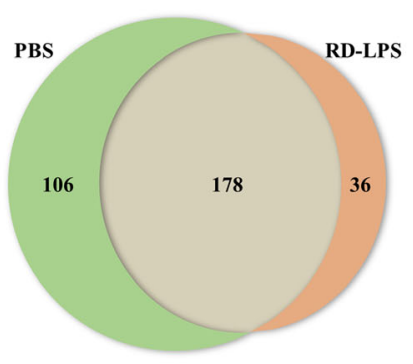

B

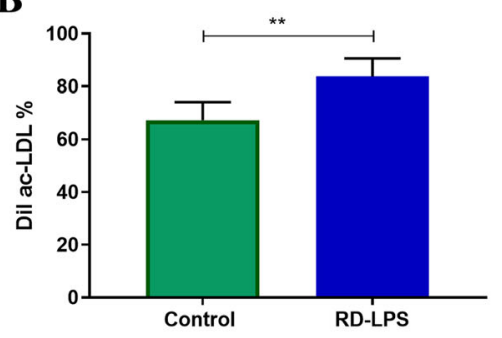

D

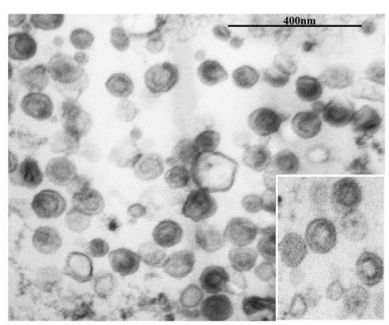

F
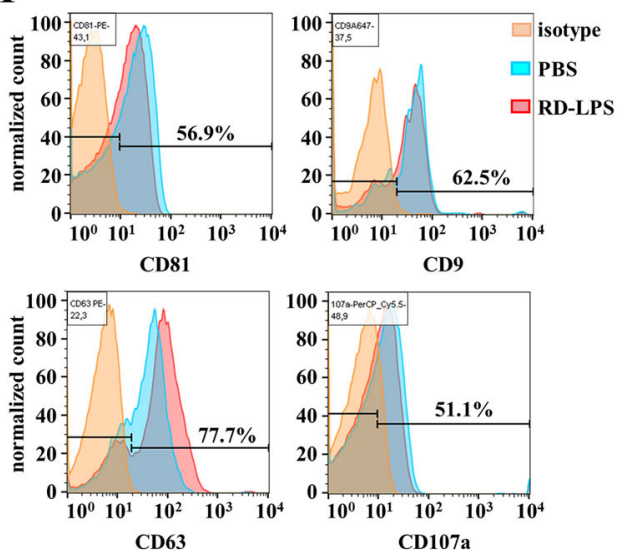

H

\begin{tabular}{llc}
\hline Protein ID & Protein name & $\begin{array}{l}\text { RD-LPS/ } \\
\text { PBS }\end{array}$ \\
\hline \hline TFR1 & Transferrin receptor protein 1 & $\mathbf{0 , 2 5}$ \\
\hline PKP1 & Plakophilin-1 & $\mathbf{0 , 2 0}$ \\
\hline B3AT & Band 3 anion transport protein & $\mathbf{0 , 2 6}$ \\
\hline CD36 & Platelet glycoprotein 4 & $\mathbf{0 , 1 5}$ \\
\hline STEA3 & Metalloreductase STEAP3 & $\mathbf{0 , 1 6}$ \\
\hline BAF & Barrier-to-autointegration factor & $\mathbf{0 , 1 8}$ \\
\hline TCP4 & $\begin{array}{l}\text { Activated RNA polymerase II } \\
\text { transcriptional coactivator p15 }\end{array}$ & $\mathbf{0 , 2 2}$ \\
\hline TKT & Transketolase & $\mathbf{0 , 2 4}$ \\
\hline CD37 & CD37 & $\mathbf{0 , 2 6}$ \\
\hline IFITM3 & Interferon-induced transmembrane protein 3 & $\mathbf{6 , 8 9}$ \\
\hline SRSF2 & Serine/arginine-rich splicing factor 2 & 4,13 \\
\hline
\end{tabular}

Fig. 2 (See legend on next page.) 


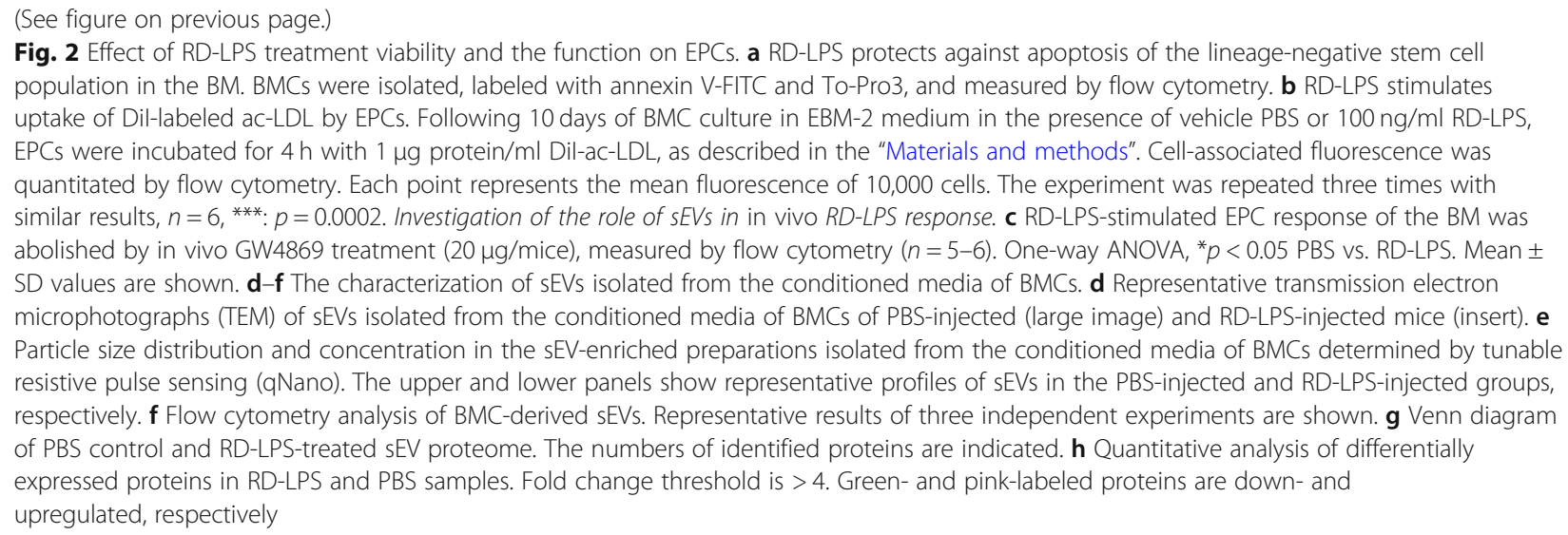

the presence of sEV markers (CD81, CD9, CD63, and CD107a) on our sEVs bound onto latex beads (Fig. 2f).

Next, to address the question which proteins could play a role in the function of RD-LPS, we performed mass spectrometry analysis of the isolated sEVs. We identified 320 proteins in sEVs. Among them, 178 were shared by EVs isolated from the conditioned medium of BMCs from PBS-injected and RD-LPS-injected animals (Fig. 2g, Additional file 5). We classified the identified proteins using gene ontology (GO), based on biological process, molecular process, and cellular function. The sEV proteins were mainly involved in angiostatin binding (GO: 0043532) and positive regulation of blood vessel endothelial cell migration (GO:0043536) (Additional file 6). Cellular components of the identified proteins revealed that most proteins were related to EVs (GO:1903561) (Additional file 6). We identified IFITM3 as a protein that showed the highest (6.89x) fold change (Fig. 2h). Using an ELISA system, we validated this MS finding (Fig. 3a). The expression of IFITM3 was low in BMC sEVs of the PBS-injected group, while it was enriched in sEVs in the RD-LPS-injected mice $(p>0.05)$. Similar results were measured from cells (data not shown). Figure $3 \mathrm{~b}$ shows that flow cytometry confirmed double (IFITM3 and CD81) positivity of the sEV-enriched preparation.

\section{Effect of IFITM3 silencing on the activation of EPCs by RD-LPS}

The role of vesicular IFITM3 on RD-LPS-induced EPCs was assessed by RNA silencing experiments. As shown in Additional file 7, high expression levels of IFITM3 were observed in RD-LPS-treated BMCs in vitro. To verify that the IFITM3 gene was silenced by sh-IFITM3, we determined the mRNA levels (Additional file 7A) in shcontrol (scrambled control) and sh-IFITM3-infected cells by qRT-PCR. Cells infected with sh-IFITM3 exhibited significantly decreased IFITM3 mRNA levels, showing a $69.8 \pm 7.5 \%$ reduction. To confirm the silencing of IFITM3, flow cytometry with IFITM3 antibodies was used. Compared with sh-control-infected cells, the IFITM3 protein level was significantly $(89.2 \pm 0.9 \%)$ decreased in BM cells infected with the sh-IFITM3 lentivirus (Additional file 7B). To determine whether IFITM3 has any impact on the RD-LPS's action, EPC number was measured by flow cytometry and ac-LDL uptake was analyzed in differentiated EPCs by fluorescent microscopy and quantified by flow cytometry. Our data indicated that depletion of IFITM3 abolished the RD-LPS induction on EPCs as compared to RD-LPStreated sh-control cells $(2.77 \pm 1.26 \%$ vs. $4.20 \pm 0.79 \%$, see Additional file 8), suggesting that the reduced expression of IFITM3 could significantly inhibit the elevation of EPCs in BM. Reduction of IFITM3 blocked the ac-LDL uptake in RD-LPS-treated cells compared to sh-control cells $(75.65 \pm 0.8 \%$ vs. $81.18 \pm 1.6 \%$, see Additional file 9). These results indicate that silencing of IFITM3 by RNAi could inhibit the effect of RD-LPS on induction of IFITM3 in BM cells.

Finally, to address the question if the IFITM3 cargo in sEVs could play a role in the effect of RD-LPS, we treated differentiated EPCs with the conditioned medium of shIFITM3-transduced BM cells. Acetylated LDL uptake was quantified in differentiated EPCs with flow cytometry (Fig. 3c). Adding conditioned medium of RD-LPS-treated BM cells to naive EPCs did not induce the further uptake of ac-LDL in sh-control+RD-LPS cells compared with shcontrol cells $(92.3 \pm 0.4 \%$ vs. $91.2 \pm 4.6 \%)$. However, downregulation of IFITM3 suppressed the activity of EPCs in sh-IFITM3+RD-LPS groups to $78.2 \pm 0.8 \%$ (see Fig. 3c), indicating that IFITM3 modulates the function of differentiated EPCs.

A graphical summary of the study is shown in Fig. 4.

\section{Discussion}

Breast cancer radiotherapy causes myocardial damage and increases the risk of cardiovascular disease and atherosclerosis [36]. The pathogenesis of radiation-induced heart disease is not completely understood: since there 


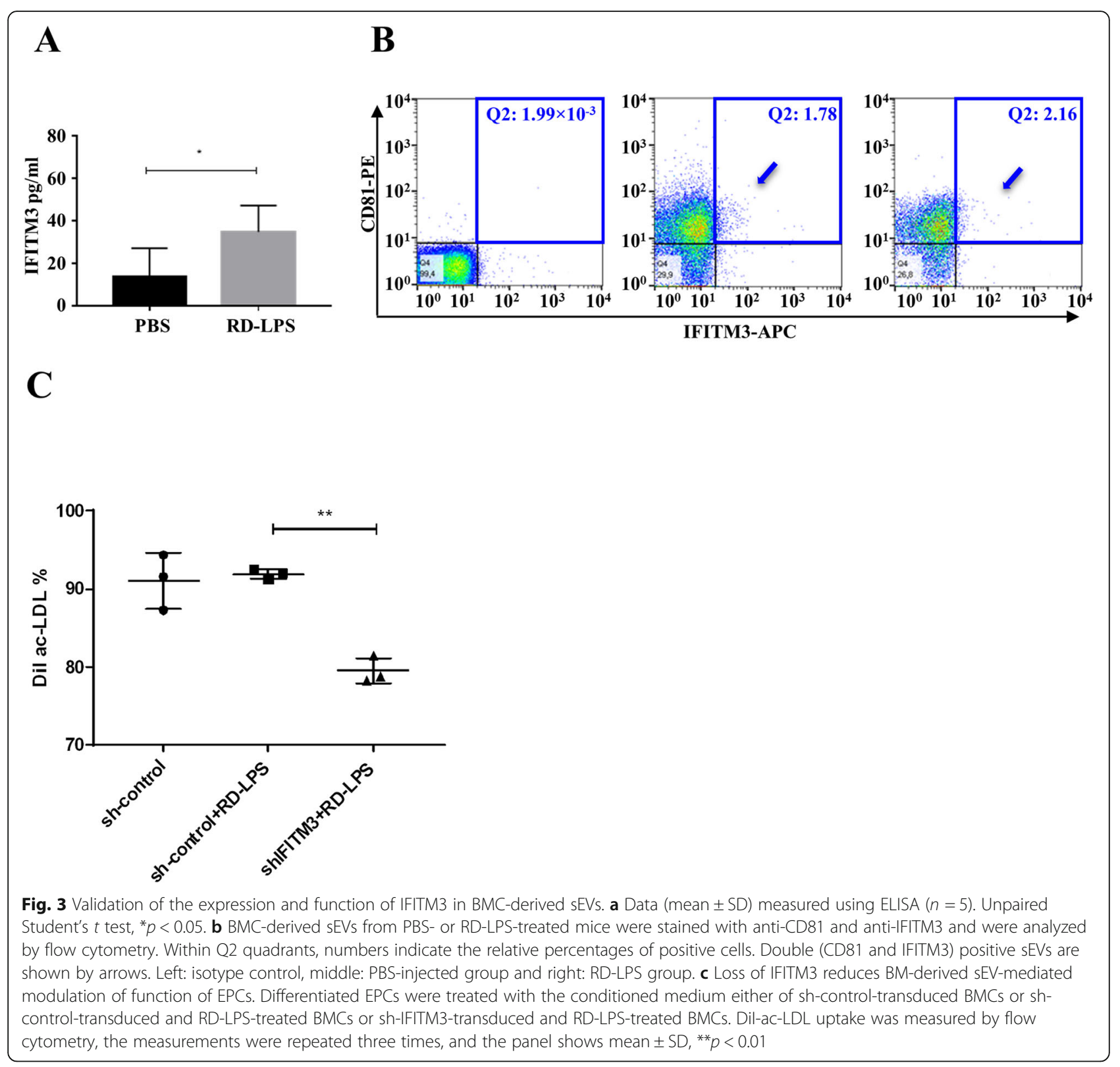

is no specific treatment for these complications, a prevention strategy is required. Many ongoing pre-clinical studies aim to elucidate molecular and cellular mechanisms of cardiovascular damage, and their goal is to find potential targets for intervention of cardiotoxicity [37]. Our data are in line with a previous study [38] showing structural damage of the myocardium in C57BL/6 mice after local heart irradiation. Although radiation induced only modest changes in cardiomyocyte morphology and radiation-induced mitochondrial DNA deletion, these were mitigated by RD-LPS. However, a single local heart dose of 16 Gy resulted in reduced survival, and RD-LPS was protective against sudden death. Similar results were presented in dog models [39]. Since the endothelium of the vasculature is thought to be one target for injury induced by radiation, pharmaceutical approaches to prevent radiation-related cardiac injury present a potential method to mitigate and treat these types of damages. Not surprisingly, there has been intense interest in cardiac injury-mitigating therapeutic cell transplants; however, the major problems with this strategy have been the poor engraftment and retention of the administered cells [40]. Activating adult stem or progenitor cells may hold more promise as a therapeutic intervention strategy for vascular regeneration [41]. BM-derived EPCs have been implicated in the repair of irradiation-induced damage of capillaries via their mobilization into circulation [42]. In the present study, we aimed to investigate 


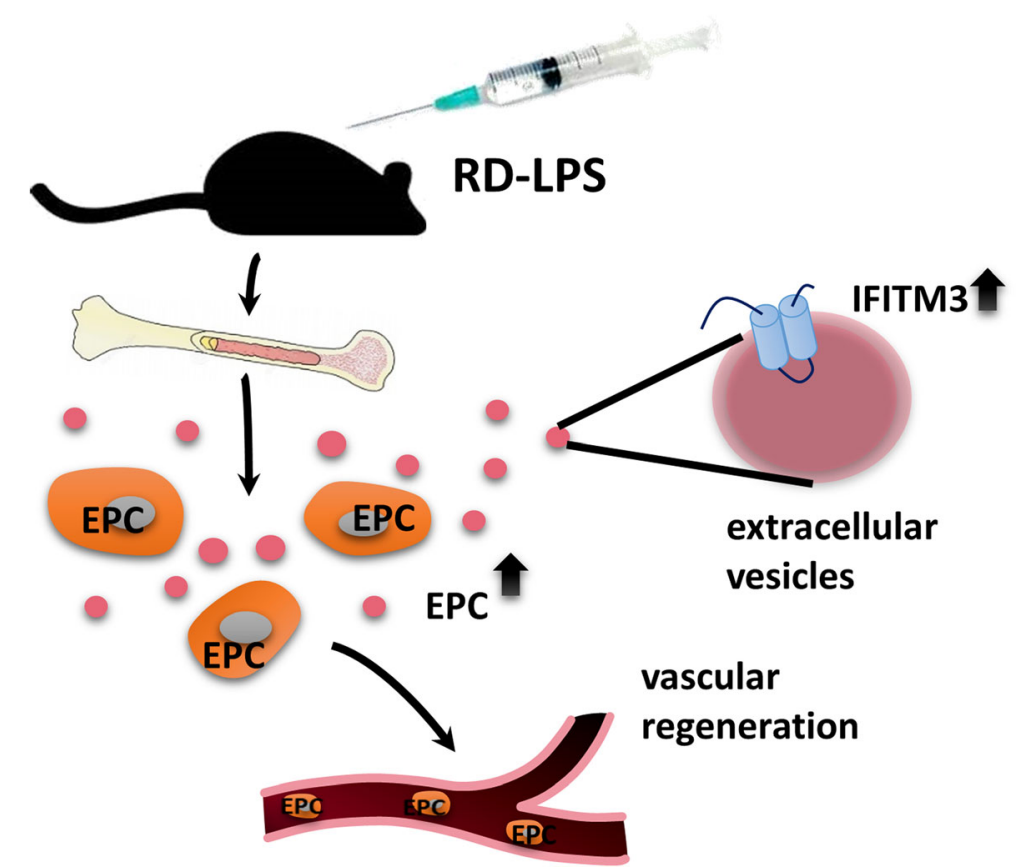

Fig. 4 Overview of RD-LPS-induced release of bone marrow-derived small EVs with IFITM3 cargo. C57/BI mice were injected i.p. with RD-LPS. After $24 \mathrm{~h}$, the amount of EPCs (depicted as orange cells with gray nuclei) were elevated both in the bone marrow and peripheral blood, potentially playing a role in the vascular regeneration of distant damaged tissues. Small EVs (dark pink dots) isolated from bone marrow cells presented upregulated IFITM3 expression (light blue)

how RD-LPS impacts the release of EPCs from the BM into the circulation and if RD-LPS could play a protective role in irradiation-induced mortality of mice. We demonstrated association of high EPC count with reduced cardiac hypertrophy and mitochondrial DNA damage, which reinforces previous findings of their protective role in cardiovascular damage [43]. Our data suggest that in RD-LPS-treated mice EPCs proliferate and migrate, increasing their number in the circulation. Thus, RD-LPS treatment could have a future impact as an initiating factor triggering EPCs. In this model, we obtained the beneficial effect of RD-LPS on survival and the treatment-associated increase of the endogenous EPCs. Several pre-clinical models have demonstrated mobilization and migration of EPCs from the bone marrow niche followed by homing to the site of vascular damage, where they modulated vascular repair [44]. Endogenous factors used therapeutically, like granulocyte colony-stimulating factor (G-CSF) and GM-CSF, are also known to induce BM-EPC mobilization and migration but may present with further complications [45]. RD-LPS has no known adverse side effects and therefore may be a promising therapeutic agent for vascular regeneration.

In an earlier study, we have shown that a low-dose local head irradiation caused cerebrovascular damage and decreased the ability of endothelial repair by circulating progenitors [46]. In addition, in a mouse model of total body irradiation, administration of G-CSF improved the survival, presumably via promoting the self-renewal of hematopoietic stem cells [47]. Radioprotective action of RD-LPS has been confirmed in several in vitro and in vivo models $[9,48]$, but it has not been tested in cardiotoxicity mouse models yet. It is accepted that radiation damages the vascular endothelial cells [38] allowing the systemwide translocation of endotoxin from intestinal bacteria. The LPS then, among other adverse effects, induces inflammation associated with cardiotoxicity [49]. Here we found that radiation-detoxified LPS protects against radiation-induced lethality in 16-Gy-exposed mice and induced release of EPCs. Indeed RD-LPS reduced the apoptosis of the stem cells in the $\mathrm{BM}$ and induced the differentiation of the EPC culture in vitro. One of the possible mechanisms of the life-extending beneficial effects of RD-LPS could be that it antagonizes radiation-induced adverse effects of LPS by blocking its receptor.

The ability of isolated EPCs to uptake acetylated lowdensity lipoprotein (DiI-ac-LDL), the classical way to define endothelial cells, was performed as described earlier [50]. Two types of EPCs can be distinguished at different time points during in vitro differentiation: early and late EPCs [51]. EPCs can take up DiI-ac-LDL and express various combinations of surface markers of the endothelial cell lineage [52]. Our cells were late EPCs with the expressed matured endothelial-specific markers. EPCs at 10 days after plating also show the cobblestone morphology typical of endothelial cells (Additional file 4, panel C). 
RD-LPS induced the number of sEVs, and we hypothesized that extracellular vesicles released from different cells are putatively involved in different aspects of the systemic response to RD-LPS, including paracrine and bystander effects. EVs may also act as stable reservoirs of biomarkers by containing specific cargo that reflect the effect of RD-LPS. We also investigated the effects of RD-LPS in vivo on the proteomic composition of BMCderived sEVs [53] and observed pronounced differences in the protein profiles of BMC- and RD-LPS-injected BMC-derived sEVs. RD-LPS-induced sEVs carried a distinct set of proteins. Among them, IFITM3 showed the highest fold change as compared to the controls, validated also by an IFITIM3 ELISA and flow cytometry analysis of sEVs. This is in line with recent findings reporting IFITM3 in sEVs mediating paracrine senescence [54]. IFITM3 is best known to play a role in the defense against virus invasion and potentially inhibits EV fusion with cells $[55,56]$. Small extracellular vesicle-associated IFITM3 has been also shown earlier to transfer an anti-viral effect to recipient cells [57]. Interestingly, IFITIM3 is present in migratory primordial germ cells and serves as a homing signal enabling cells to respond to environmental signals guiding their migration [58]. Recently, IFITIM3 has also been reported as a biomarker of several tumors $[59,60]$. Moreover, IFITM3 was detected in endothelial cells and several cancer cell-derived sEVs by MS [61, 62]. We speculated that IFITM3 was necessary for the activation of differentiated EPCs and RD-LPS-induced EPC activation based on an early stem cell induction phase. Surprisingly, in our in vitro experiments, the RD-LPS effect was not transmitted through EVs. However, our data suggest that the presence of IFITM3 in the cells is necessary for RDLPS-induced EPC activation, in agreement with a recent study pinpointing the possible role of IFITM3 in glioma cell growth and migration [63].

Our results suggest that the expression of the transmembrane protein IFITM3 is strongly upregulated in RD-LPS-treated mice. In addition, IFITIM3 is associated with BMC-derived sEVs and may provide a promising candidate biomarker of the RD-LPS effect. Thus, assessment of cellular and EV-associated IFITIM3 may possibly find a place among strategies for evaluating the regeneration potential of BM.

\section{Supplementary information}

Supplementary information accompanies this paper at https://doi.org/10. 1186/s13287-019-1417-4.

Additional file 1. The effect of RD-LPS injection on the count of peripheral blood mononuclear cells (PBMCs) and bone marrow cells (BMCs) of 16 Gy local heart-irradiated mice. Results of time dependent alterations of number of PBMCs and BMCs following irradiation and RD-LPS treatment.
Additional file 2. RD-LPS mitigates irradiation-induced cardiac hypertrophy. Irradiation-stimulated increase in heart weight at 250 days is abrogated by the addition of RD-LPS.

Additional file 3. RD-LPS reduces apoptosis of Lin- stem cells. The representative figures show the gating strategies.

Additional file 4. RD-LPS stimulates uptake of Dil-ac-LDL by EPCs. The representative images show the Dil-ac-LDL uptake.

Additional file $\mathbf{5}$ List of small extracellular vesicle proteins identified by LC-MS/MS in BM-derived cells. List of proteins identified by LC-MS/MS are given in separate sheets. Sheet 'PBS' shows the result of measurement on controls $(n=7)$; the results of the treated group $(n=9)$ are listed on sheet 'RD-LPS'.

Additional file 6. Detailed results of the enrichment analysis. Output from the g:Profiler enrichment analysis for the three main Gene Ontology categories (Biological Process, Cellular Component, Molecular function).

Additional file 7. Lentivirus-mediated gene silencing of IFITM3 in BM cells. Results of qRT-PCR (A) and flow cytometric evaluation (B).

Additional file 8. Effect of lentivirus-mediated gene silencing of IFITM3 on EPC activation in BMCs. Flow-cytometry based measurement of the number of EPCS.

Additional file 9. Effect of lentivirus-mediated gene silencing of IFITM3 on the function of differentiated EPCs. Results of Dil-ac-LDL analyzed by flow-cytometry (A) and representative images (B).

\section{Abbreviations}

RD-LPS: Radio-detoxified lipopolysaccharide; sEV: Small extracellular vesicles; IFITM3: Interferon-induced transmembrane protein-3; BM: Bone marrow; BMCs: Bone marrow cells; EPCs: Endothelial progenitor cells; VEGFR2: Vascular endothelial growth factor receptor 2; GW4869: 2-Propenamide, 3,3'-(1,4-phenylene)bis[N-[4-(4,5-dihydro-1H-imidazol-2-yl)phenyl]hydrochloride; LC-MS: Liquid chromatography/mass spectrometry; TEM: Transmission electron microscopy; G-CSF: Granulocyte colonystimulating factor

\section{Acknowledgements}

Not applicable.

\section{Authors' contributions}

$\mathrm{HH}$ designed and carried out the experiments. NS and GS carried out the irradiation experiments. VL performed the ELISA tests. KP and ÁKo participated in the flow cytometry analysis. LK and AT executed the histomorphological analyses. LT carried out the MS analysis. ÁKi prepared the EM images. $L B, H H$, and ElB wrote the manuscript. All authors read and approved the final manuscript.

\section{Funding}

This work was supported by National Research, Development and Innovation Office NKFIH, Hungary, OTKA1 1958, OTKA120237, NVKP_16-1-2016-0017, Ministry for National Economy of Hungary, VEKOP-2.3.2-16-2016-00002 and VEKOP-2.3.3-15-2016-00016, Higher Education Institutional Excellence Program Therapeutic development, and H2020-MSCA-ITN-2017-722148 TRAIN EV.

\section{Availability of data and materials}

All data generated or analyzed during this study are included in this published article and its supplementary information files.

Ethics approval and consent to participate

All animal studies were conducted according to the 1998 XXVIII Hungarian law about animal protection and welfare. Animal studies were approved by the Budapest and Pest County Administration Office Food Chain Safety and Animal Health Board (permit number: 22.1/2703/3/2011 and PE/EA/1426-7/2018).

Consent for publication

No applicable.

Competing interests

The authors declare that they have no competing interests. 


\section{Author details}

'Department of Genetics, Cell- and Immunobiology, Semmelweis University, Budapest, Hungary. ${ }^{2}$ National Research Directorate for Radiobiology and Radiohygiene, National Public Health Center, Budapest, Hungary. ${ }^{3} \mathrm{MS}$ Proteomics Research Group, Research Centre for Natural Sciences, Hungarian Academy of Sciences, Budapest, Hungary. ${ }^{4}$ Institute of Experimental Medicine, Hungarian Academy of Sciences, Budapest, Hungary. ${ }^{5}$ MTA-SE Immune-Proteogenomics Extracellular Vesicles Research Group, Semmelweis University, Budapest, Hungary.

Received: 16 February 2019 Revised: 8 September 2019 Accepted: 12 September 2019 Published online: 29 October 2019

\section{References}

1. Duma MN, Molls M, Trott KR. From heart to heart for breast cancer patients - cardiovascular toxicities in breast cancer radiotherapy. Strahlenther Onkol. 2014;190:5-7. https://doi.org/10.1007/s00066-013-0465-4.

2. Wang Y, Probin V, Zhou D. Cancer therapy-induced residual bone marrow injury: mechanisms of induction and implication for therapy. Curr Cancer Ther Rev. 2006;2:271-9. https://doi.org/10.2174/157339406777934717.

3. Whelan TJ, Levine M, Julian J, Kirkbride P, Skingley P, Ontario Clinical Oncology Group. The effects of radiation therapy on quality of life of women with breast carcinoma: results of a randomized trial. Cancer. 2000; 88:2260-6. https://doi.org/10.1002/(SICI)1097-0142(20000515)88:10<2260:: AID-CNCR9>3.0.CO;2-M.

4. Raghunathan D, Khilji MI, Hassan SA, Yusuf SW. Radiation-induced cardiovascular disease. Curr Atheroscler Rep. 2017;19:22. https://doi.org/10. 1007/s11883-017-0658-X.

5. Kim JH, Jenrow KA, Brown SL. Mechanisms of radiation-induced normal tissue toxicity and implications for future clinical trials. Radiat Oncol J. 2014; 32:103-15. https://doi.org/10.3857/roj.2014.32.3.103.

6. Mezzaroma E, Di X, Graves P, Toldo S, Van Tassell BW, Kannan H, et al. A mouse model of radiation-induced cardiomyopathy. Int J Cardiol. 2012;156: 231-3. https://doi.org/10.1016/j.ijcard.2012.01.038.

7. Walaszczyk A, Szołtysek K, Jelonek K, Polańska J, Dörr W, Haagen J, et al. Heart irradiation reduces microvascular density and accumulation of HSPA1 in mice. Strahlenther Onkol. 2018;194:235-42. https://doi.org/10.1007/ s00066-017-1220-z.

8. Tapio S. Pathology and biology of radiation-induced cardiac disease. J Radiat Res. 2016;57:439-48. https://doi.org/10.1093/jrr/rrw064.

9. Bertók L. Radio-detoxified endotoxin activates natural immunity: a review. Pathophysiology. 2005;12:85-95. https://doi.org/10.1016/j. pathophys.2005.02.004.

10. Bertok $L$, Berczi I. Nomenclature and significance of innate/natural immune mechanisms and of species specific resistance. Adv Neuroimmune Biol. 2011;1:11-24. https://doi.org/10.3233/NIB-2011-002.

11. Kawamoto A, Losordo DW. Endothelial progenitor cells for cardiovascular regeneration. Trends Cardiovasc Med. 2008;18:33-7. https://doi.org/10.1016/ j.tcm.2007.11.004.

12. Allan DS, Morgan SC, Birch PE, Yang L, Halpenny MJ, Gunanayagam A, et al. Mobilization of circulating vascular progenitors in cancer patients receiving external beam radiation in response to tissue injury. Int J Radiat Oncol Biol Phys. 2009;75:220-4. https://doi.org/10.1016/j.ijrobp.2009.04.033.

13. Hung SC, Kuo KL, Huang HL, Lin CC, Tsai TH, Wang CH, et al. Indoxyl sulfate suppresses endothelial progenitor cell-mediated neovascularization. Kidney Int. 2016:89:574-85. https://doi.org/10.1016/j.kint.2015.11.020.

14. Becker CM, Beaudry P, Funakoshi T, Benny O, Zaslavsky A, Zurakowski D, et al. Circulating endothelial progenitor cells are up-regulated in a mouse model of endometriosis. Am J Pathol. 2011;178:1782-91. https://doi.org/10. 1016/j.ajpath.2010.12.037.

15. Heissig B, Hattori K, Dias S, Friedrich M, Ferris B, Hackett NR, et al. Recruitment of stem and progenitor cells from the bone marrow niche requires MMP-9 mediated release of kit-ligand. Cell. 2002;109:625-37. https://doi.org/10.1016/S0092-8674(02)00754-7.

16. Xu MY, Ye ZS, Song XT, Huang RC. Differences in the cargos and functions of exosomes derived from six cardiac cell types: a systematic review. Stem Cell Res Ther. 2019;10:194. https://doi.org/10.1186/s13287-019-1297-7.

17. György B, Szabó TG, Pásztói M, Pál Z, Misják P, Aradi B, et al. Membrane vesicles, current state-of-the-art: emerging role of extracellular vesicles. Cell Mol Life Sci. 2011;68:2667-88. https://doi.org/10.1007/s00018-011-0689-3.
18. Théry C, Witwer KW, Aikawa E, Alcaraz MJ, Anderson JD, Andriantsitohaina $R$, et al. Minimal information for studies of extracellular vesicles 2018 (MISEV2018): a position statement of the International Society for Extracellular Vesicles and update of the MISEV2014 guidelines. J Extracell Vesicles. 2018;7(1):1535750. https://doi.org/10.1080/20013078.2018.1535750.

19. Sluijter JPG, Davidson SM, Boulanger CM, Buzás El, de Kleijn DPV, Engel FB, et al. Extracellular vesicles in diagnostics and therapy of the ischaemic heart: position paper from the working group on cellular biology of the heart of the European Society of Cardiology. Cardiovasc Res. 2018;114:19-34. https:// doi.org/10.1093/cvr/cvx211.

20. Evans SS, Lee DB, Han T, Tomasi TB, Evans RL. Monoclonal antibody to the interferon-inducible protein Leu-13 triggers aggregation and inhibits proliferation of leukemic B cells. Blood. 1990;76:2583-93.

21. Tanaka SS, Matsui Y. Developmentally regulated expression of mil-1 and mil-2, mouse interferon-induced transmembrane protein like genes, during formation and differentiation of primordial germ cells. Mech Dev. 2002; 119(Suppl):S261-S7. https://doi.org/10.1016/S0925-4773(03)00126-6.

22. Diamond MS, Farzan M. The broad-spectrum antiviral functions of IFIT and IFITM proteins. Nat Rev Immunol. 2013;13:46-57. https://doi.org/10.1038/nri3344.

23. Gabriels K, Hoving S, Seemann I, Visser NL, Gijbels MJ, Pol JF, et al. Local heart irradiation of $\mathrm{ApoE}(-/-)$ mice induces microvascular and endocardial damage and accelerates coronary atherosclerosis. Radiother Oncol. 2012; 105:358-64. https://doi.org/10.1016/j.radonc.2012.08.002.

24. Sievert W, Stangl S, Steiger K, Multhoff G. Improved overall survival of mice by reducing lung side effects after high-precision heart irradiation using a small animal radiation research platform. Int J Radiat Oncol Biol Phys. 2018; 1(101):671-9. https://doi.org/10.1016/j.jijobp.2018.02.017.

25. Schneider CA, Rasband WS, Eliceiri KW. NIH image to ImageJ: 25 years of image analysis. Nat Methods. 2012;9:671-5.

26. Dory Video: Using ImageJ to measure cell number and cross-sectional area of confocal images. https://www.youtube.com/watch?v=leicxaeMUwA. Accessed on 30 June 2019

27. Maas SL, De Vrij J, Broekman ML. Quantification and size-profiling of extracellular vesicles using tunable resistive pulse sensing. J Vis Exp. 2014;19: e51623. https://doi.org/10.3791/51623.

28. Osteikoetxea X, Benke M, Rodriguez M, Pálóczi K, Sódar BW, Szvicsek Z, et al. Detection and proteomic characterization of extracellular vesicles in human pancreatic juice. Biochem Biophys Res Commun. 2018;499:37-43. https:// doi.org/10.1016/j.bbrc.2018.03.107.

29. Turiák L, Misják P, Szabó TG, Aradi B, Pálóczi K, Ozohanics O, et al. Proteomic characterization of thymocyte-derived microvesicles and apoptotic bodies in BALB/c mice. J Proteome. 2011;74:2025-33. https://doi.org/10.1016/j.jprot. 2011.05.023.

30. Reimand J, Arak T, Adler P, Kolberg L, Reisberg S, Peterson H, et al. g:Profiler-a web server for functional interpretation of gene lists (2016 update). Nucleic Acids Res. 2016;44:W83-9. https://doi.org/10.1093/nar/gkw199.

31. Cox J, Mann M. MaxQuant enables high peptide identification rates, individualized p.p.b.range mass accuracies and proteome-wide protein quantification. Nat Biotechnol. 2008;26:1367-72. https://doi.org/10.1038/nbt.1511.

32. Monceau V, Llach A, Azria D, Bridier A, Petit B, Mazevet M, et al. Epac contributes to cardiac hypertrophy and amyloidosis induced by radiotherapy but not fibrosis. Radiother Oncol. 2014;111:63-71. https://doi. org/10.1016/.radonc.2014.01.025.

33. Zhang SB, Maguire D, Zhang M, Zhang Z, Zhang A, Yin L, et al. The murine common deletion: mitochondrial DNA 3,860-bp deletion after irradiation. Radiat Res. 2013;180:407-13. https://doi.org/10.1667/RR3373.1.

34. Yang J, li M, Kamei N, Alev C, Kwon SM, Kawamoto A, et al. CD34+ cells represent highly functional endothelial progenitor cells in murine bone marrow. PLoS One. 2011;6:e20219. https://doi.org/10.1371/journal.pone.0020219.

35. Kosaka N, Iguchi H, Yoshioka Y, Takeshita F, Matsuki Y, Ochiya T. Secretory mechanisms and intercellular transfer of microRNAs in living cells. J Biol Chem. 2010;285:17442-52. https://doi.org/10.1074/jbc.M110.107821.

36. Darby SC, Cutter DJ, Boerma M, Constine LS, Fajardo LF, Kodama K, et al. Radiation-related heart disease: current knowledge and future prospects. Int J Radiat Oncol Biol Phys. 2010;76:656-65. https://doi.org/10.1016/j.jirobp. 2009.09.064.

37. Boerma M, Hauer-Jensen M. Potential targets for intervention in radiationinduced heart disease. Curr Drug Targets. 2010;11:1405-12. https://doi.org/ 10.2174/1389450111009011405.

38. Seemann I, Gabriels K, Visser NL, Hoving S, te Poele JA, Pol JF, et al. Irradiation induced modest changes in murine cardiac function despite progressive 
structural damage to the myocardium and microvasculature. Radiother Oncol. 2012;103:143-50. https://doi.org/10.1016/j.radonc.2011.10.011.

39. Bertók L, Juhász-Nagy A, Sótonyi P. Prevention of cardiac damage induced by formyl-leurosine, a potent cytostatic agent, by radio-detoxified endotoxin (Tolerin). Immunopharmacology. 1984;8:13-7.

40. Badorff C, Brandes RP, Popp R, Rupp S, Urbich C, Aicher A, et al. Transdifferentiation of blood-derived human adult endothelial progenitor cells into functionally active cardiomyocytes. Circulation. 2003;107:1024-32. https://doi.org/10.1161/01.cir.0000051460.85800.bb.

41. Cho HJ, Kim HS, Lee MM, Kim DH, Yang HJ, Hur J, et al. Mobilized endothelial progenitor cells by granulocyte-macrophage colony-stimulating factor accelerate reendothelialization and reduce vascular inflammation after intravascular radiation. Circulation. 2003;108:2918-25. https:/doi.org/ 10.1161/01.CIR.0000097001.79750.78.

42. Prisco AR, Hoffmann BR, Kaczorowski CC, McDermott-Roe C, Stodola TJ, Exner EC, et al. Tumor necrosis factor a regulates endothelial progenitor cell migration via CADM1 and NF-kB. Stem Cells. 2016;34:1922-33. https://doi. org/10.1002/stem.2339

43. Budzyń M, Gryszczyńka B, Boruczkowski M, Kaczmarek M, Begier-Krasińska B, Osińska A, et al. The potential role of circulating endothelial cells and endothelial progenitor cells in the prediction of left ventricular hypertrophy in hypertensive patients. Front Physiol. 2019. https:/doi.org/10.3389/fphys.2019.01005.

44. Haider KH, Aziz S, Al-Reshidi MA. Endothelial progenitor cells for cellular angiogenesis and repair: lessons learned from experimental animal models. Regen Med. 2017;12:969-82. https://doi.org/10.2217/rme-2017-0074.

45. Volpi I, Perruccio K, Tosti A, Capanni M, Ruggeri L, Posati S, et al. Postgrafting administration of granulocyte colony-stimulating factor impairs functional immune recovery in recipients of human leukocyte antigen haplotype-mismatched hematopoietic transplants. Blood. 2001;97:2514-21. https://doi.org/10.1182/blood.v97.8.2514.

46. Sándor N, Walter FR, Bocsik A, Sántha P, Schilling-Tóth B, Léner V, et al. Low dose cranial irradiation-induced cerebrovascular damage is reversible in mice. PLoS One. 2014;9:e1 12397. https://doi.org/10.1371/journal.pone.0112397.

47. Patchen ML, Fischer R, MacVittie TJ. Effects of combined administration of interleukin-6 and granulocyte colony-stimulating factor on recovery from radiation-induced hemopoietic aplasia. Exp Hematol. 1993;21:338-44.

48. Berczi I, Bertok L, Chow DA. Host defence: an interaction of neuroendocrine-, metabolic- and immune mechanisms in the interest of survival. In: Bertok L, Chow DA, editors. Natural Immunity. Elsevier B.V. 2005. p. 3-25. doi: https://doi.org/10.1016/S1567-7443(05)80006-7

49. McIntyre CW, Harrison LE, Eldehni MT, Jefferies HJ, Szeto CC, John SG, et al. Circulating endotoxemia: a novel factor in systemic inflammation and cardiovascular disease in chronic kidney disease. Clin J Am Soc Nephrol. 2011;6:133-41. https://doi.org/10.2215/CJN.04610510.

50. Bueno-Betí C, Novella S, Lázaro-Franco M, Pérez-Cremades D, Heras M Sanchís J, et al. An affordable method to obtain cultured endothelial cells from peripheral blood. J Cell Mol Med. 2013;17:1475-83. https://doi.org/10. $1111 / \mathrm{jcmm} .12133$.

51. Lee PS, Poh KK. Endothelial progenitor cells in cardiovascular diseases. World J Stem Cells. 2014;6:355-66. https://doi.org/10.4252/wjsc.v6.i3.355.

52. Yang N, Li D, Jiao P, Chen B, Yao S, Sang H, et al. The characteristics of endothelial progenitor cells derived from mononuclear cells of rat bone marrow in different culture conditions. Cytotechnology. 2011;63:217-26. https://doi.org/10.1007/s10616-010-9329-2.

53. De Jong OG, Verhaar MC, Chen Y, Vader P, Gremmels H, Posthuma G, et al. Cellular stress conditions are reflected in the protein and RNA content of endothelial cell-derived exosomes. J Extracell Vesicles. 2012;1:1. https://doi. org/10.3402/jev.v1i0.18396.

54. Borghesan M, Fafián-Labora J, Eleftheriadou O, Carpintero-Fernández $\mathrm{P}$, Paez-Ribes M, Vizcay-Barrena G, et al. Small extracellular vesicles are key regulators of non-cell autonomous intercellular communication in senescence via the interferon protein IFITM3. Cell Rep. 2019;27:3956-71.e6. https://doi.org/10.1016/j.celrep.2019.05.095.

55. Joung I, Angeletti PC, Engler JA. Functional implications in apoptosis by interferon inducible gene product $1-8 \mathrm{D}$, the binding protein to adenovirus preterminal protein. J Microbiol. 2003:41:295-9.

56. Perreira JM, Chin CR, Feeley EM, Brass AL. IFITMs restrict the replication of multiple pathogenic viruses. J Mol Biol. 2013;425:4937-55. https://doi.org/10. 1016/j.jmb.2013.09.024

57. Tanaka SS, Yamaguchi YL, Tsoi B, Lickert H, Tam PP. IFITM/mil/Fragilis family proteins IFITM1 and IFITM3 play distinct roles in mouse primordial germ cell homing and repulsion. Dev Cell. 2005;9:745-56. https://doi.org/10.1016/j. devcel.2005.10.010.

58. Zhu X, He Z, Yuan J, Wen W, Huang X, Hu Y, et al. IFITM3-containing exosome as a novel mediator for anti-viral response in dengue virus infection. Cell Microbiol. 2015;17:105-18. https://doi.org/10.1111/cmi.12339.

59. Li D, Peng Z, Tang H, Wei P, Kong X, Yan D, et al. KLF4-mediated negative regulation of IFITM3 expression plays a critical role in colon cancer pathogenesis. Clin Cancer Res. 2011;17:3558-68. https://doi.org/10.1158/ 1078-0432.CCR-10-2729.

60. Yount JS, Moltedo B, Yang YY, Charron G, Moran TM, López CB, et al. Palmitoylome profiling reveals S-palmitoylation-dependent antiviral activity of IFITM3. Nat Chem Biol. 2010;6:610-4. https://doi.org/10.1038/nchembio.405.

61. Mathivanan S, Lim JW, Tauro BJ, Ji H, Moritz RL, Simpson RJ. Proteomics analysis of A33 immunoaffinity-purified exosomes released from the human colon tumor cell line LIM1215 reveals a tissue-specific protein signature. Mol Cell Proteomics. 2010;9:197-208. https://doi.org/10.1074/mcp.M900152-MCP200.

62. Hurwitz SN, Rider MA, Bundy JL, Liu X, Singh RK, Meckes DG Jr. Proteomic profiling of NCl-60 extracellular vesicles uncovers common protein cargo and cancer type-specific biomarkers. Oncotarget. 2016;7:86999-7015. https://doi.org/10.18632/oncotarget.13569.

63. Zhao B, Wang H, Zong G, Li P. The role of IFITM 3 in the growth and migration of human glioma cells. BMC Neurol. 2013;13:210. https://doi.org/ 10.1186/1471-2377-13-210.

\section{Publisher's Note}

Springer Nature remains neutral with regard to jurisdictional claims in published maps and institutional affiliations.
Ready to submit your research? Choose BMC and benefit from:
- fast, convenient online submission
- thorough peer review by experienced researchers in your field
- rapid publication on acceptance
- support for research data, including large and complex data types
- gold Open Access which fosters wider collaboration and increased citations
- maximum visibility for your research: over $100 \mathrm{M}$ website views per year
At BMC, research is always in progress.
Learn more biomedcentral.com/submissions 